\title{
Are cognitive interventions for Multiple Sclerosis effective and feasible?
}

\author{
Rosana Magalhães $^{\mathrm{a}, *}$, Jorge Alves ${ }^{\mathrm{a}}$, Roger E. Thomas ${ }^{\mathrm{b}}$, Nancy Chiaravalloti ${ }^{\mathrm{c}, \mathrm{d}}$, Óscar F. Gonçalves ${ }^{\mathrm{a}, \mathrm{e}, \mathrm{f}}$, \\ Agavni Petrosyan ${ }^{\mathrm{a}, \mathrm{g}}$ and Adriana Sampaio ${ }^{\mathrm{a}}$ \\ ${ }^{a}$ Neuropsychophysiology Laboratory, CIPsi, School of Psychology, University of Minho, Braga, Portugal \\ ${ }^{\mathrm{b}}$ Department of Family Medicine, Health Sciences Centre, University of Calgary, Calgary, AB, Canada \\ ${ }^{\mathrm{c}}$ Neuropsychology and Neuroscience Laboratory (NNL), Kessler Foundation, West Orange, NJ, USA \\ ${ }^{\mathrm{d}}$ Department of Physical Medicine \& Rehabilitation, Rutgers the State University of New Jersey, NJ, USA \\ ${ }^{\mathrm{e}}$ Department of Counseling and Applied Educational Psychology, Bouvé College of Health Sciences, Northeastern \\ University, Boston, MA, USA \\ ${ }^{\mathrm{f}}$ Spaulding Center of Neuromodulation, Department of Physical Medicine \& Rehabilitation, Spaulding Rehabili- \\ tation Hospital and Massachusetts General Hospital, Harvard Medical School, Boston, MA, USA \\ ${ }^{\mathrm{g}}$ Department of Cognitive Sciences, University of California, Irvine, CA, USA
}

\begin{abstract}
.
Purpose: Fifty percent of patients with Multiple Sclerosis (MS) are estimated to have cognitive impairments leading to considerable decline in productivity and quality of life. Cognitive intervention has been considered to complement pharmacological treatments. However, a lack of agreement concerning the efficacy of cognitive interventions in MS still exists. A systematic review and meta-analysis was conducted to assess the effects of cognitive interventions in MS.

Methods: To overcome limitations of previous meta-analyses, several databases were searched only for Randomized Clinical Trials (RCTs) with low risk of bias.

Results: Five studies (total of 139 participants) met our eligibility criteria. Although good completion and adherence rates were evident, we found no evidence of intervention effects on cognition or mood in post-intervention or follow-up assessments.

Conclusions: This is the first meta-analysis assessing the effects of cognitive intervention in MS including only RCTs with comparable conditions. Research regarding efficacy, cost-effectiveness and feasibility is still in its infancy. Caution is advised when interpreting these results due to the small number of RCTs meeting the inclusion criteria. Considering the costs of disease, good completion and adherence rates of this approach, further research is warranted. Recommendations concerning improved research practices in the field are presented as well.
\end{abstract}

Keywords: Rehabilitation, multiple sclerosis, systematic review, meta-analysis, feasibility

\section{Introduction}

Early studies have reported that $40 \%$ of individuals afflicted by Multiple Sclerosis (MS) suffer from cogni-

\footnotetext{
*Corresponding author: Rosana Magalhães, Laboratório de Neuropsicofisiologia, Escola de Psicologia, Universidade do Minho Campus de Gualtar, 4710-057 Braga, Portugal. Tel.: +351 253 601398; Fax: +351 253 604224; E-mail: rosana.magalhaes@ psi.uminho.pt.
}

tive deficits (Rao et al., 1991), with more recent studies increasing this estimate to 50\% (Benedict et al., 2006). Cognitive impairments are often identified in the early phases of the disease and frequently progress over time (Amato et al., 2001). In people with MS, cognitive impairments often lead to disruptions in work, daily activities, family, interpersonal life (DeLuca, 2006), and an overall decline in Quality of Life (QoL) (Grima et al., 2000). 
Commonly impaired cognitive functions include learning and memory (between 40 to $60 \%$ of patients) (DeLuca et al., 1994); divided attention (McCarthy et al., 2005); working memory (Rao et al., 1993); executive functioning (mainly on concept-formation, planning, and organization skills) (Brassington and Marsh, 1998); and speed of processing (Chiaravalloti and DeLuca, 2008). Additionally, a large body of literature unveiled global intellectual functioning (Brassington and Marsh, 1998) and language skills (DeLuca, 2006) to be largely preserved in people with MS. Recent research has shown deficits in speed of processing to be the primary cognitive deficit in MS (DeLuca et al., 2004), possibly also contributing to other cognitive deficits such as learning and memory (Chiaravalloti et al., 2013).

Pharmacological treatments, including drugs such as donepezil, memantine, rivastigmine, methylphenidate, and l-amphetamine have been examined for their impact on memory, information processing and divided attention (Amato et al., 2013; He et al., 2011). While some positive results have been noted (Krupp et al., 2004) they were often followed by a failure to replicate the results (Amato et al., 2013; Krupp et al., 2011), therefore the impact of such treatments remains to be debatable (He et al., 2011). One exception is L-amphetamine sulfate, which has shown some potential in improving learning and memory in MS (Sumowski et al., 2011). Nevertheless, more research is needed to assess the efficacy of pharmacological agents in enhancing Multiple Sclerosis-related cognitive impairments (Morrow et al., 2009).

Currently, non-pharmacological treatments for cognitive impairments in MS are being developed. Because of the encouraging results with healthy aging populations (Lustig et al., 2009) and several neurological diseases such as Alzheimer's disease (Alves et al., 2013), cognitive interventions have also been tested for cognitive impairment in MS. Cognitive interventions often include cognitive training and rehabilitation focusing on one (Chiaravalloti et al., 2005; Vogt et al., 2009) or several domains of cognition (Brissart et al., 2010; Stuifbergen et al., 2012). Interventions may be delivered by a training software (Fink et al., 2010; Solari et al., 2004; Stuifbergen et al., 2012; Tesar et al., 2005) or treatment manuals, using pencil and paper approaches to teach patients the use of internal memory aids and compensatory strategies (Chiaravalloti et al., 2005; das Nair and Lincoln, 2012).
Some studies have also noted an improvement in emotional functioning following cognitive rehabilitation (Brenk et al., 2008; Mattioli et al., 2010) while others found no effect of cognitive intervention on patients' quality of life (Hildebrandt et al., 2007; Lincoln et al., 2002; Mattioli et al., 2010) and cognition (Lincoln et al., 2002; Solari et al., 2004).

Considering these mixed results, previous metaanalyses (Rosti-Otajarvi and Hamalainen, 2011; Thomas, et al., 2006) examined the efficacy of several non-pharmacological interventions in MS for cognitive impairments, depression, anxiety and coping strategies. However, combining different types of interventions and study designs in the same metaanalysis can lead to misleading conclusions concerning the efficacy of cognitive interventions. For example, a quantitative meta-analysis (das Nair et al., 2012) study combined different types of memory outcomes (memory for word list, story memory, and memory scales/composites) into the same memory comparison and found lack of evidence concerning the efficacy of cognitive interventions. In a more recent review paper (Amato et al., 2013), no quantitative results were provided, postponing the emergence of definite conclusions. Furthermore, only few studies included longitudinal assessments and, when considered in previous meta-analysis, no significant results have been found at the follow-up moments (das Nair et al., 2012; Rosti-Otajarvi and Hamalainen, 2011).

In order to overcome the limitations of previous meta-analyses, the present review compares studies including only Randomized Controlled Trials at low risk of bias for randomization, adherence to protocol and attrition as well as comparable interventions.

\section{Methods}

\subsection{Data sources and eligibility criteria}

The following databases were searched for Randomized Controlled Trials of cognitive interventions in MS from inception to April 4th, 2013: PubMed, PsychINFO and EMBASE. The Cochrane Library (Cochrane CENTRAL Register of Controlled Trials and Cochrane Reviews) was searched in addition to reference lists from four major reviews (das Nair et al., 2012; O'Brien et al., 2008; Rosti-Otajarvi \& Hamalainen, 2011; Thomas, Thomas et al., 2006). No language limitations 


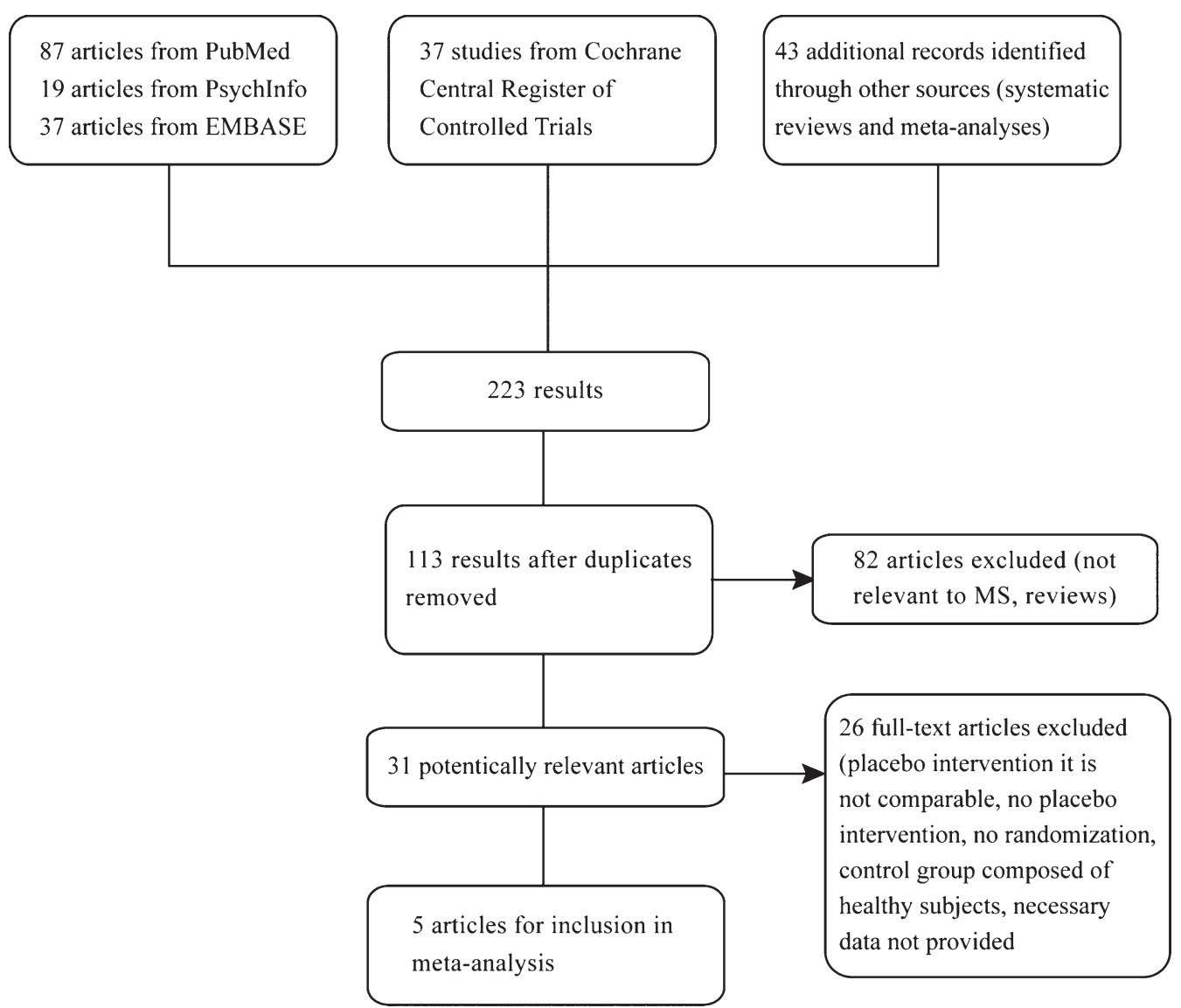

Fig. 1. Flow diagram.

Table 1

Search expressions for PubMed

Search terms used for Randomized Controlled Trials of cognitive interventions in MS:

(Memory OR Working memory OR Attention OR Concentration OR "Information processing" OR "speed of processing"

OR "Executive Functioning" OR "executive functions" OR Reasoning OR Language OR "Verbal fluency" OR

Visuo-spatial OR Visuoconstructive OR visuospatial OR Cognitive OR Cognition OR Neurocognitive OR

Neuropsychological OR Compensatory OR Remediation OR remediative OR Restorative OR restoration OR Learning

OR Cognitive-motor) AND (Intervention OR Stimulation OR Rehabilitation OR Program OR Programme OR Training

OR Retraining) AND ("multiple sclerosis" OR "demyelinating disease" OR "acute disseminated encephalomyelitis" OR

"encephalomyelitis disseminate" OR "disseminated sclerosis" OR "demyelinating autoimmune disease") AND

("randomized controlled trial" OR "randomized clinical trial" OR "randomized controlled study" OR "randomized

controlled trial” OR "randomized clinical trial” OR "randomized controlled study" OR "randomized pilot study" OR

"randomized pilot study" OR "controlled study")

Search terms used in the PubMed for costs or cost-effectiveness of cognitive intervention in Multiple Sclerosis: multiple

sclerosis, cognitive, cognition, cost, medical care, expenditures, medical care expenses, cost-effectiveness and cost benefit.

were applied. See Fig. 1 Flow diagram (Moher et al., 2009) and Table 1.

Two authors (RM and JA) independently applied these inclusion criteria to abstracts and full-texts:

1. Randomized Controlled Trials only;
2. Patients with confirmed Multiple Sclerosis diagnosis, using accepted standardized neurological criteria (e.g., McDonald criteria of 2001, revisions of 2005 and 2010 or Poser's 1983 criteria);

3. Patients with MS that received cognitive intervention; 
4. Intervention delivered by trained technicians/research team member;

5. Mock intervention employed for comparison;

6. Pre- and post-assessment (sufficient data to calculate effect size).

The following exclusion criteria were applied:

1. Non-randomized studies;

2. Pharmacological trials;

3. Diagnosis other than Multiple Sclerosis;

4. Interventions such as "Neuropsychological" counseling, cognitive behavioral therapy (CBT) or educational therapy (techniques with intent to modify behavior, to manage stress and teaching of Psychoeducation related to the disease);

5. Conditions of cognitive intervention dissimilar in frequency of intervention sessions (2 times a week vs. 3 times a week, etc.); duration of the intervention program ( 4 weeks vs. 6 weeks, etc.); duration of intervention sessions ( $50 \mathrm{~min}$. vs. $90 \mathrm{~min}$., etc.); and contact with the therapist (one group meeting with therapists and being part of a program vs. other group waiting to be contacted);

6. Interventions comparing MS groups with healthy control groups.

None of the retrieved studies reported costs or cost-effectiveness for which an additional search was undertaken in PubMed (search terms in Table 1).

For the feasibility analysis we recorded the number of dropouts after randomization in each study, the reasons for dropping out, and the number of missed sessions. We calculated the completion rate (percentage of people who completed the intervention programs) and adherence rate for each group (number of sessions attended divided by the total number of program sessions).

\subsection{Data extraction and analysis}

In order to establish the validity of eligible randomized controlled trials, two authors (RM and JA) independently reviewed the articles and assessed the randomization and concealment of allocation, blinding of patients, personnel and outcome assessment, attrition and reporting bias. For data analyses, data and risk of bias scores were entered into the Cochrane Collaboration's Review Manager Software Version 5.2.3 for Windows (RevMan, 2012).
All available information from studies on cognition, mood, psychomotor, subjective measures of cognitive functions, and quality of life were collected. Studies were excluded if they lacked test scales or units.

Mean scores, standard deviations of post-treatment assessments and number of patients per group at randomization was recorded. When available, mean change scores from pre- to post-treatment were recorded instead and data collected for the longest follow-up interval. When heterogeneity was low (i.e., $\mathrm{I}^{2}<50$ ), continuous data were analyzed by mean differences using the fixed effects model (with $95 \%$ confidence intervals, CI).

Given that neuropsychological test outcomes varied across studies, they were grouped into typical domains. When studies measured a domain utilizing different measures, standardized mean differences were employed. By default, the software considered a lower value as a better outcome, therefore the default setting was used for measuring mood or memory complains.

Forest plots were then generated for each domain. Visual inspection of graphs and the $\mathrm{I}^{2}$ Index was used to assess heterogeneity.

\section{Results}

\subsection{Included studies}

The search identified 113 studies (after removal of duplicates). After refining the search, 82 articles were excluded because they were either review, noninterventional or pharmacological treatment studies. Although 31 potential candidate articles were considered for the meta-analysis, after full-texts were inspected several studies had to be excluded if control groups were missing; the comparison group was composed of healthy subjects; compared interventions were not comparable, patients were not randomly assigned; intervention(s) focused on domains other than cognition; or authors could not provide necessary data (Solari et al., 2004).

Five articles (Cerasa et al., 2013; Chiaravalloti et al., 2005; Chiaravalloti et al., 2012; das Nair \& Lincoln, 2012; Mendozzi et al., 1998) with low risk of bias met our inclusion criteria and were selected for quantitative analysis (Fig. 1 Flow diagram), summing up 139 participants in total. 


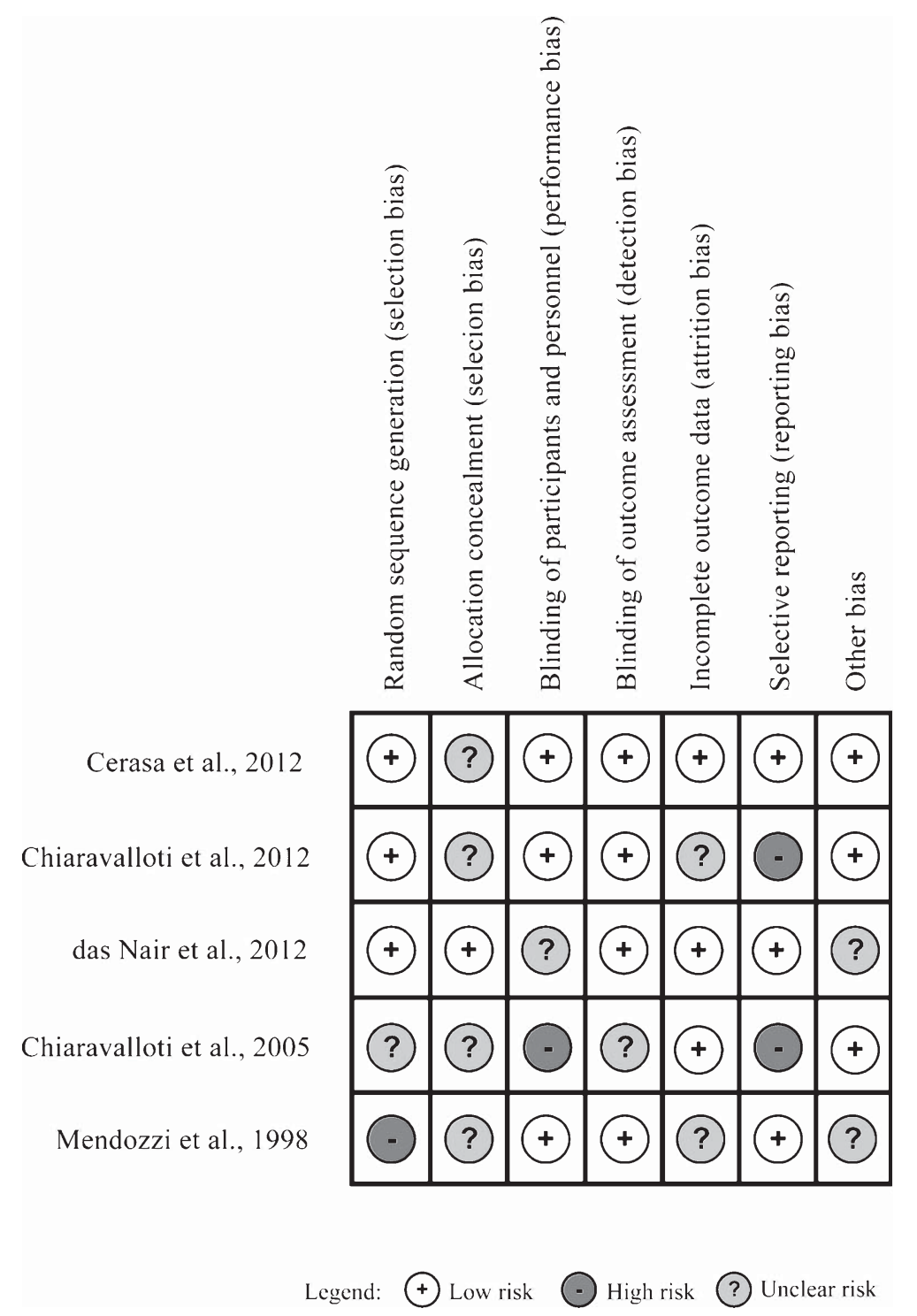

Fig. 2. Risk of bias summary graph. Rows correspond to the included articles in the meta-analysis and each column corresponds to the parameters of the risk of bias assessment. Each circle represents the risk of bias assessment of a particular parameter in each study.

Risk of bias was independently assessed by two authors (RM and JA). Risk of bias summary graph is displayed in Fig. 2.

Further characteristics of included studies and the respective outcome measures are presented in Table 2.

\subsection{Cognitive intervention efficacy analysis}

Studies employed a vast diversity of measures/tests of cognitive outcomes such as memory, speed of pro- cessing and mood. Therefore, ten comparisons were constructed: overall memory functioning, episodic verbal memory (including wordlist total learning; immediate memory of story recall; and delayed recall of wordlist), working memory, visual memory, subjective memory (immediate and long-term effects), speed of processing, depressive (immediate and long-term effects) and anxiety symptoms/complaints.

Results of cognitive intervention effects are shown in Table 3 and in Fig. 3. 
Table 2

Descriptions/Characteristics of the included studies

\begin{tabular}{|c|c|c|c|}
\hline $\begin{array}{l}\text { Study } \\
\text { Sample details (diagnosis, } \\
\text { clinical course, physical and } \\
\text { cognitive status) }\end{array}$ & Intervention Condition $(n)$ & Comparison Condition $(n)$ & Measures/Outcomes \\
\hline $\begin{array}{l}\text { (Cerasa et al., 2013) Clinically } \\
\text { definite RRMS. }\end{array}$ & $\begin{array}{l}\text { Computer-assisted training } \\
\text { (software RehaCom) of several } \\
\text { attention ability and } \\
\text { information processing tasks } \\
(n=13)\end{array}$ & $\begin{array}{l}\text { Computerized tests of visuomotor } \\
\text { coordination tasks, using an } \\
\text { in-house software }(n=13)\end{array}$ & Brief repeatable battery $(\mathrm{BRB})$ \\
\hline 26 RRMS & $\begin{array}{l}\text { (12 sessions of } 1 \text {-hour, twice a } \\
\text { week, } 6 \text { weeks) }\end{array}$ & $\begin{array}{l}\text { (12 sessions of } 1 \text {-hour, twice a } \\
\text { week, } 6 \text { weeks) }\end{array}$ & Trail Making Test A, B \\
\hline $\begin{array}{l}\text { Patients with Expanded } \\
\text { Disability Status Scale (EDSS) } \\
\text { score ranging from } 0 \text { to } 4 \text {. }\end{array}$ & & & Mini-Mental State Examination \\
\hline $\begin{array}{l}\text { Patients "with predominant } \\
\text { deficits in either attention } \\
\text { and/or information processing } \\
\text { speed, working memory, and/or } \\
\text { executive functioning" but } \\
\text { without severe cognitive } \\
\text { impairment (patients who } \\
\text { failed a maximum of } 2 \text { tests). }\end{array}$ & & & $\begin{array}{l}\text { Beck Depression Inventory } \\
\text { State-Trait Anxiety Inventory } \\
(\mathrm{Y} 1, \mathrm{Y} 2)\end{array}$ \\
\hline $\begin{array}{l}\text { (Chiaravalloti et al., 2012) } \\
\text { Clinically definite }\end{array}$ & $\begin{array}{l}\text { Program using modified Story } \\
\text { Memory Technique (mSMT) } \\
(n=8)\end{array}$ & $\begin{array}{l}\text { Control group included tasks } \\
\text { such as reading the same stories } \\
\text { and answering questions }(n=8)\end{array}$ & California Verbal Learning Test) \\
\hline $\begin{array}{l}\text { Multiple Sclerosis (2001 } \\
\text { McDonald's criteria). 11/16 } \\
\text { RRMS }\end{array}$ & $\begin{array}{l}\text { (10 sessions of } 45-60 \mathrm{~min}, \text { twice } \\
\text { a week, } 5 \text { weeks) }\end{array}$ & $\begin{array}{l}\text { (10 sessions of } 45-60 \mathrm{~min}, \text { twice } \\
\text { a week, } 5 \text { weeks })\end{array}$ & $\begin{array}{l}\text { Prose Memory test (Memory } \\
\text { Assessment Scale) }\end{array}$ \\
\hline $\begin{array}{l}\text { Patients' physical disease } \\
\text { severity was measured by the } \\
\text { Ambulation Index } \\
\text { (experimental } \\
\text { group }=2.13 \pm 1.73 \text {; control } \\
\text { group }=3.75 \pm 1.39) \text {. }\end{array}$ & & & Rivermead Total Profile Score \\
\hline \multirow[t]{2}{*}{$\begin{array}{l}\text { All patients were determined to } \\
\text { have impaired verbal new } \\
\text { learning (as measured by } \\
\text { performance at an adaptation } \\
\text { of the Buschke Selective } \\
\text { Reminding Test). }\end{array}$} & & & Judgment Line Orientation test \\
\hline & & & $\begin{array}{l}\text { Symbol Digit Modalities Test } \\
\text { Memory Functioning } \\
\text { Questionnaire } \\
\text { State-Trait Anxiety Inventory } \\
\text { (Y1, Y2) } \\
\text { Chicago Multidimensional } \\
\text { Depression Inventory } \\
\text { Neuroimaging (cerebral } \\
\text { activation during fMRI tasks) }\end{array}$ \\
\hline $\begin{array}{l}\text { (das Nair and Lincoln, 2012) } \\
\text { Diagnosis was verified by } \\
\text { hospital or general practitioner }\end{array}$ & $\begin{array}{l}\text { Restitution program }(n=17) \text { : use } \\
\text { of internal memory aids; } \\
\text { exercises to practice encoding } \\
\text { and retrieval and attention } \\
\text { retraining exercises }\end{array}$ & $\begin{array}{l}\text { Compensation program }(n=12) \text { : } \\
\text { use of internal and external } \\
\text { memory aids }(2 \text { individual }+10 \\
\text { weekly group sessions of } \\
\text { 1.5-hour) }\end{array}$ & Verbal and visual memory tests \\
\hline 29 MS patients & $\begin{array}{l}\text { (2 individual }+10 \text { weekly group } \\
\text { sessions of } 1.5 \text {-hour) }\end{array}$ & & $\begin{array}{l}\text { Tests for executive abilities, } \\
\text { mood and disability }\end{array}$ \\
\hline
\end{tabular}


Table 2

(Continued)

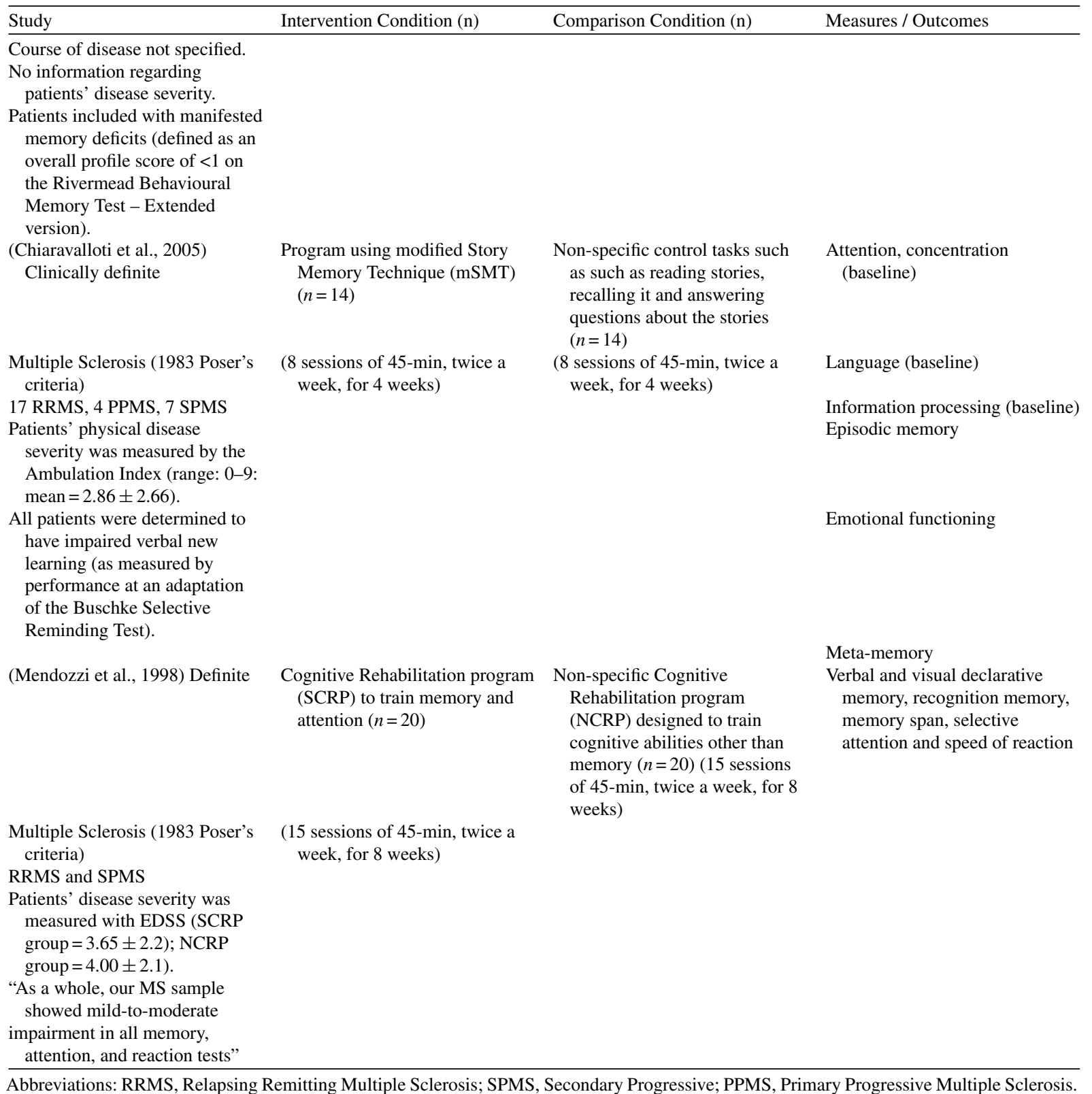

No significant effects were identified in overall memory functioning (standardized mean difference, -0.02 ; $95 \% \mathrm{CI},-0.62-0.57$ ); learning wordlists (standardized mean difference, $0.11 ; 95 \% \mathrm{CI},-0.27-0.50$ ); delayed recall of wordlists (standardized mean difference, 0.19 ; 95\% CI, -0.44-0.82); immediate memory in story recall (standardized mean difference, -0.27 ;
95\% CI, $-0.80-0.26$ ); working memory (standardized mean difference, $0.28 ; 95 \% \mathrm{CI},-0.25-0.81$ ); visual memory (standardized mean difference, 0.02; 95\% CI, -0.49-0.54), subjective memory assessment (standardized mean difference, $-0.44 ; 95 \% \mathrm{CI}$, $-0.93-0.05$ ), speed of processing (mean difference, -0.13 ; 95\% CI, -6.73-6.46), mood (standardized 


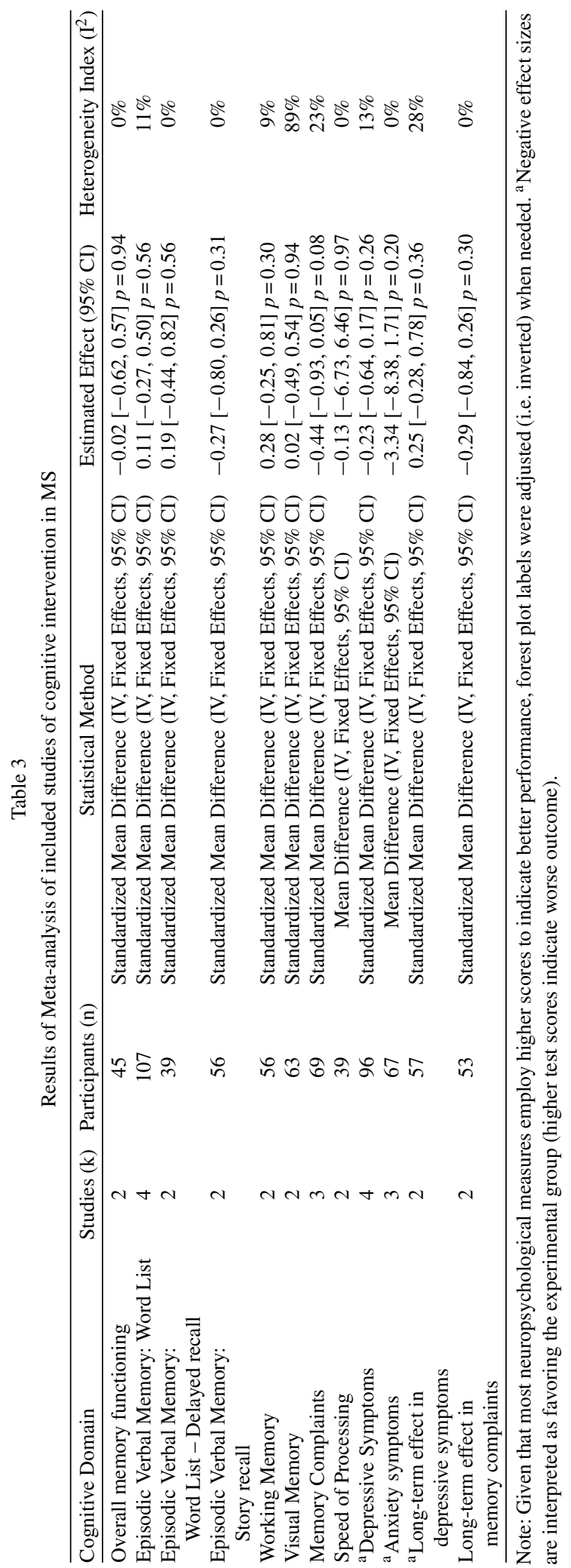



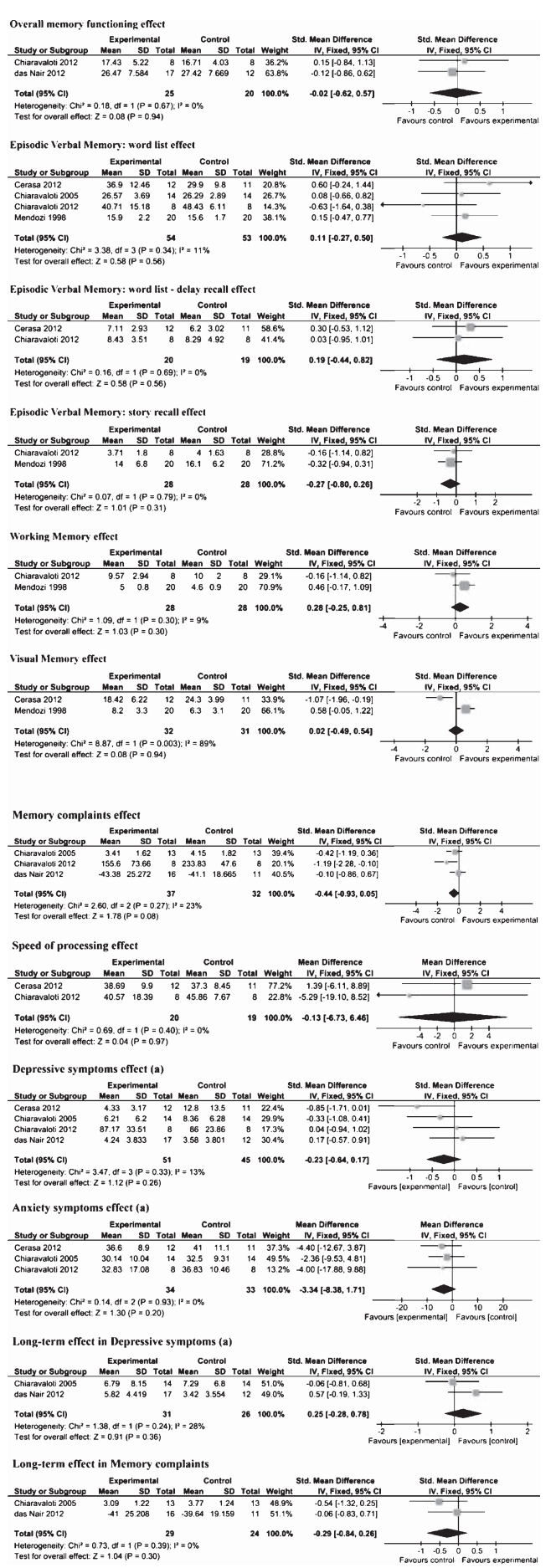

Fig. 3. Forest plots. Note: Given that most neuropsychological measures employ higher scores to indicate better performance, forest plot labels were adjusted (i.e. inverted) when needed. (a) Negative effect sizes are interpreted as favoring the experimental group (higher test scores indicate worse outcome). mean difference, -0.23 ; 95\% CI, $-0.64-0.17$ ), or anxiety symptoms (mean difference, $95 \% \mathrm{CI},-3.34$; -8.38-1.71).

Concerning the long-term effects of cognitive intervention, no significant effects were identified in mood (standardized mean difference, $0.25 ; 95 \%$ CI, $-0.28-0.78$ ) or memory complaints (standardized mean difference, -0.29 ; 95\% CI, -0.84-0.26).

No evidence of heterogeneity was found (the $\mathrm{I}^{2}$ index was always <50\%); (Higgins et al., 2003) except for visual memory comparison $(89 \%)$.

\subsection{Cost-effectiveness data analysis}

The search for costs of cognitive interventions run in PubMed yielded 25 results. Only four of these studies assessed costs of different interventions (exercise and cognitive-behavioral therapy), with three of them being trial protocols with no available data. Moss-Morris and colleagues (2012) analyzed the effect of an Internetbased cognitive behavioral therapy self-management program for fatigue in MS while presenting only the costs related to utilized services. They concluded that the costs were very similar between intervention and control groups with minimal gains in terms of measures of quality adjusted life years (QALYs), with no estimation of costs related to the implementation of the programs.

\subsection{Analysis of feasibility}

The completion rate, for the experimental intervention ranged between $92.3 \%$ and $100 \%$, and control intervention between $84.6 \%$ and $100 \%$. The adherence rate was estimated to be $100 \%$ (both for the intervention and control groups). See Table 4.

\section{Discussion}

The present study is the first meta-analysis focusing on cognitive intervention trials at low risk of bias including active control condition/groups.

From an initial pool of more than one hundred results, only 5 studies met our eligibility criteria, with a total of 139 MS patients. Despite the fact that individual studies showed positive results, when pooled in the meta-analysis we found no significant effects in any of the analyzed cognitive or emotional domains, either for immediate post-intervention or follow-up assessments. 


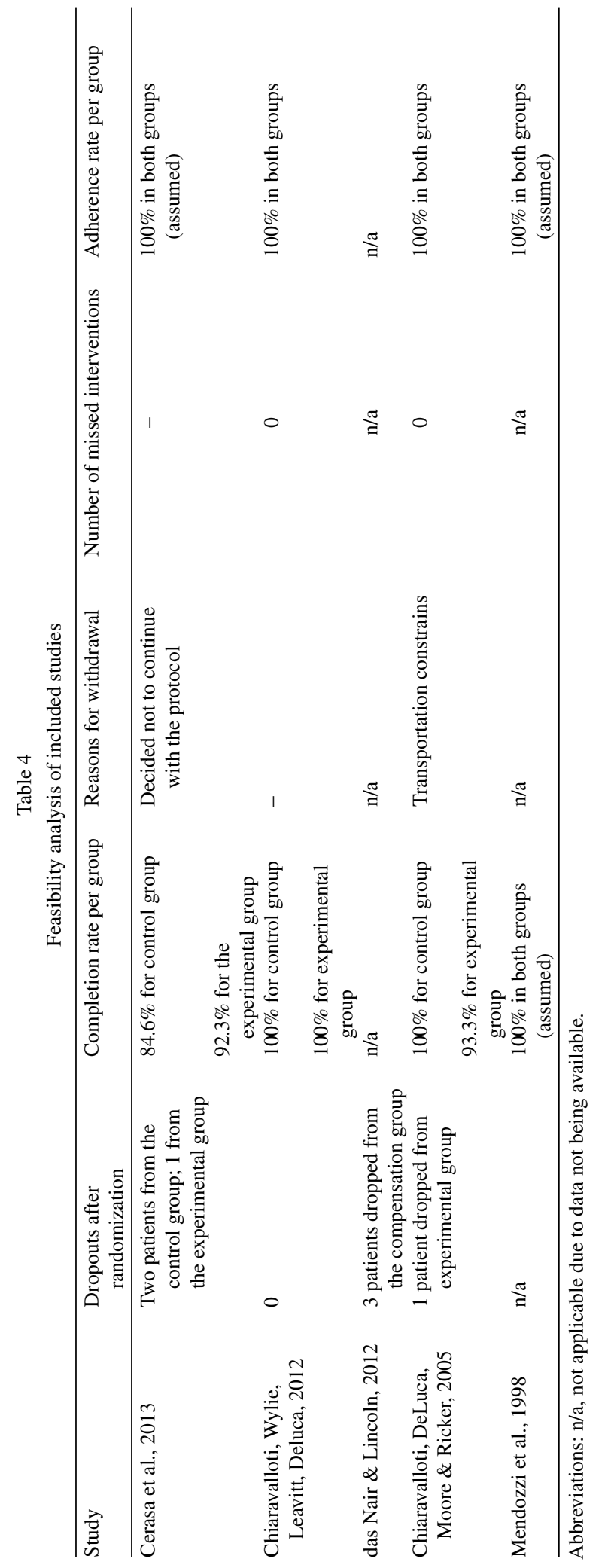


Our results are not much different from previously published studies (das Nair et al., 2012; Rosti-Otajarvi and Hamalainen, 2011; Thomas et al., 2006). Regarding longitudinal effects, there are promising findings from Mattioli, Stampatori et al. (2012) who found improvements of short duration cognitive training to remain stable at 6 months after the end of the program; and from another group (Rosti-Otajarvi et al., 2013a) who displayed positive effects of cognitive intervention on perceived cognitive deficits that were maintained for nine months. However, since up to now only few studies include follow-up assessments, it is still too soon to assume that (all) cognitive intervention effects can be maintained afterwards.

The results obtained in the current meta-analysis are likely to be due to the very limited number of studies at low risk of bias qualified for inclusion, as well as the very limited number of domains for the comparison (almost no overlapping of outcomes across studies and few studies per domain). Considering the positive results of different studies, it seems viable to hypothesize that availability of only a small number of high-quality studies in literature, could have diminished intervention effects, making it impossible to capture its full capacity. The inclusion of global cognitive status and an implementation of a standard cognitive assessment protocol might greatly enhance findings of the future studies.

Concerning the risk of bias, the allocation concealment, blinding of participants and personnel as well as selective reporting, are important issues to be adequately implemented in future studies. It is thus evident that the field of cognitive rehabilitation in MS is limited with only few high-quality studies having been completed up to date. Additionally, as shown before (Rosti-Otajarvi and Hamalainen, 2011), the overall quality of cognitive rehabilitation research in MS is in dire need of improvement. Specific methodological recommendations to advance the field include:

- An increase in number of participants (the biggest sample in this meta-analysis was 60 patients, 20 in each group);

- A consensus to implement the same battery of neuropsychological tests across studies/worldwide. This procedure would strengthen, both in number and in quality, the comparisons between studies in future meta-analysis. In this regard, BICAMS (Brief International Cognitive Assessment for Multiple Sclerosis) might pro- vide a viable option (a worldwide online registry of a standard neuropsychological battery for MS patients) (Benedict et al., 2012).

- Assessment of specific and transfer effects of progress across intervention sessions, by documenting tasks and cognitive measures performance for the assessment of abilities trained during interventions; [Some of the currently available software provide log files of performance records (e.g., levels of difficulty, time to completion) (Vogt et al., 2009)].

- In relation to the previous topic, the implementation of behavioral and functional outcomes should be improved as well. Functional or daily living scales could be used to assess generalization of gains to functional/practical aspects of life [e.g., pegboard tests, Timed Instrumental Activities of Daily Living (Goverover et al., 2007; Owsley et al., 2002) visual awareness tests (Ball et al., 2002)]. Additionally, subjective measures of cognitive functioning should be added more consistently across all studies. Eventually, if these measures are included, one could possibly apprehend if improvements in neuropsychological tests would also be accompanied by amelioration in perceived (subjective) cognitive functioning. In the study of Rosti-Otajarvi and coworkers (2013b), for example, improvement was manifested in (reduced) perceived cognitive problems reported by the patients.

- Establishment of therapy parameters (e.g., contact with the therapist, duration, and frequency) is crucial. Without an inclusion of this information, it is impossible for readers to understand the number of needed sessions and the necessary duration of sessions/programs for effective treatments of cognitive impairments. This issue should be addressed both for research (NMSS, 2008) as well as for clinical purposes (NICE, 2003). Evidence regarding this issue is rather scarce (e.g., comparison of a highly intensive vs. distributed training) (Vogt et al., 2009).

- Estimation of costs of the therapeutic approach. Studies should provide costs of intervention (including therapists' salary, materials, software and manuals), calculated per session and per program. These data are fundamental for policy makers/governmental entities in deciding if these approaches are cost-effective and can be made available to patients (NICE, 2003). 
- Use of Web-based interventions for the efficient registration of outcomes so they can be compared with more traditional paper-and-pencil interventions, particularly in terms of costs.

Thus, many questions, pertaining to the efficacy of cognitive intervention, remain to be answered, mainly due to methodological questions. However, the present results must be interpreted cautiously. Importantly, "a lack of evidence; however, does not equate to evidence against a procedure" (Freeman and Playford, 2012). Factors that may contribute to the lack of consistent evidence across studies should be acknowledged: 1) Neuropsychological tests might not be sensitive to subtle gains from the cognitive intervention, despite the implemented cognitive approach. For instance, even though patients might feel less burdened with cognitive slowing and use more internal strategies to cope with memory impairments neuropsychological tests might not capture these changes. 2) Statistical significance is typically overvalued and few acknowledge the importance of a clinically meaningful change that may result from cognitive intervention. Benedict and Walton (2012) have recently drawn attention to this issue, referring to the use of patient-reported outcomes (PROs) and of clinically meaningful change in MS studies. Namely, Food and Drug Administration (FDA) Guidance highlights that, besides providing statistical evidence of a given treatment, one should also examine the presence of individual meaningful change (Benedict and Walton, 2012). Additionally, one should also account for the "amount of change that has actual meaning to a patient's daily life" (Benedict and Walton, 2012) and might not be measured by neuropsychological tests. Determining what is a clinically meaningful change for primary outcomes in clinical trials and the development of outcome measures tackling patient' experience and goals, could be a noteworthy path to follow. For example, Morrow and colleagues (2010) verified that a decline of four points in Symbol Digit Modalities Test (Smith, 1982) could distinguish MS patients in terms of employment status. Could this value be used as a criterion for determining efficacy of given cognitive treatment? This question remains to be explored.

Another issue is the duration and intensity of interventions. According to Shatil and colleagues (2010), several cognitive interventions need a longer duration to yield tangible results. Thus, for brain reorganiza- tion to occur, or new strategies learned, one would have to undergo more treatment to maximize the therapeutic benefits. The above-mentioned group (Shatil et al., 2010) showed that an intensive (3 sessions per week for 12-weeks) home-based cognitive intervention could be effective in improving memory and processing speed. Of note, the longest intervention included in our meta-analysis comprised of 15 sessions (twice a week), shorter and less intensive than the schedule proposed by Shatil and colleagues (2010) which might explain the lack of affirmative results in the present meta-analysis.

Additionally, feasibility of cognitive interventions is seldom reported. So far, there is only adherence data from a home-based cognitive training program (Shatil et al., 2010), with $57.6 \%$ of the participants completing more than half of the prescribed sessions of the cognitive intervention program at home (unprompted and with no reminders). Our feasibility analysis of cognitive interventions, however, yielded good completion and adherence rates (ranging between $92.3 \%$ and $100 \%$; and $100 \%$ respectively).

Another important issue is the personalization of cognitive training for each patient. Such personalization requires that the patient's baseline cognitive assessment to be the starting point for determining areas in need of improvement. Concerning tailormade interventions, some authors (Shatil et al., 2010; Vogt et al., 2009) used an interactive-adaptive system to continually adapt to the level of difficulty of the patient's performance. These are some important aspects to be taken into consideration when designing future cognitive intervention trials. It should also be further investigated, whether cognitive intervention could complement pharmaceutical interventions for delaying or decreasing Multiple Sclerosis-related cognitive impairments. Considering the fact that combination of different approaches could yield far more potential than a single treatment used in isolation (Goverover et al., 2011; NICE, 2003), it is very relevant to evaluate the combined clinical relevance of different interventions. For example, there is evidence of the beneficial impact of physical fitness on the cognition of MS patients (Sandroff et al., 2014) and on neurogenesis and hippocampal function in elderly (Erickson et al., 2011). Some authors argue that combined interventions (i.e. cognitive plus physical training) might be the most effective approach in preventing cognitive decline (Oswald et al., 2006). RCTs using cognitive training 
in combination with physical exercise in MS populations are warranted (Motl et al., 2011). Nevertheless, the compared value of individual and combined approaches as brain health promoting therapies needs further evidence for the establishment of firm conclusions.

Finally, it is also important to explore those who benefit most from cognitive interventions, as well as the common factors that may underlie the potential improvements. Factors such as cognitive reserve (Stern, 2002), education (Scarpazza et al., 2013), the existence of cognitive impairment and employment status are known to mediate cognitive functioning in MS (Strober et al., 2013; Sumowski et al., 2013; Sumowski et al., 2010). Hence, post-hoc analysis in clinical trials might be helpful in identifying individual differences that may account for variability in response to treatments. In the same line of thought, it is also important to provide cognitive intervention only to patients who have clearly demonstrated cognitive impairments, since these are the ones who are more likely to benefit (Chiaravalloti et al., 2005; RostiOtajarvi et al., 2013b).

Regarding study limitations the present metaanalysis is constrained by the utilized strict criteria in selecting only RCTs, which resulted in few studies being included in meta-analysis. Methodological limitations, such as comparing groups under different conditions, found in several studies, prevented us from comparing more results.

\section{Conclusion}

Multiple Sclerosis disease entails numerous implications. For instance, inability to sustain employment (Grima et al., 2000), decline in Quality of Life (Kobelt et al., 2006), early-retiring patients with high levels of dependence from informal care, add up to be quite costly. Considering that brain plasticity has been shown to occur throughout lifespan (Landi and Rossini, 2010) and "is the most efficient way to preserve brain function despite progressive loss of structural resources" (Scarpazza et al., 2013), cognitive intervention is considered a worthwhile option for managing cognitive impairments in MS. For further development and optimization of this approach, an additional investment of time and resources in the cognitive rehabilitation field, particularly in this clinical group, is still in much demand.
In the present study, although cognitive intervention presents good adherence and completion rates, feasibility and cost-effectiveness are in need for further exploration as it has been recently recommended for other neurodegenerative pathologies such as in Alzheimer's disease (Alves et al., 2013). To create practice guidelines, cognitive intervention parameters, such as optimal duration and intensity of those interventions should be established as well. Future clinical trials should work on improving methodological concerns, such as allocation, concealment, blinding of participants and personnel, to facilitate the establishment of cognitive intervention efficacy in MS.

\section{Acknowledgments}

R.M. and J.A. are supported by doctoral Grants from Fundação para a Ciência e Tecnologia (FCT) (SFRH/BD/65213/2009, SFRH/BD/64457/2009 and co-funded by FSE/POPH). A.S. is funded for the project PIC/IC/83290/2007, supported by FEDER (POFC-COMPETE) and FCT to develop and assess the effectiveness of a cognitive stimulation tool for Portuguese clinicians.

\section{References}

Alves, J., Magalhaes, R., Thomas, R.E., Goncalves, O.F., Petrosyan, A., \& Sampaio, A. (2013). Is there evidence for cognitive intervention in Alzheimer disease? A systematic review of efficacy, feasibility, and cost-effectiveness. Alzheimer Dis Assoc Disord, 27(3), 195-203.

Amato, M.P., Langdon, D., Montalban, X., Benedict, R.H., Deluca, J., Krupp, L.B., et al., (2013). Treatment of cognitive impairment in multiple sclerosis: Position paper. J Neurol, 260(6), 1452-1468.

Amato, M.P., Ponziani, G., Siracusa, G., \& Sorbi, S. (2001). Cognitive dysfunction in early-onset multiple sclerosis: A reappraisal after 10 years. Arch Neurol, 58(10), 1602-1606.

Ball, K., Berch, D.B., Helmers, K.F., Jobe, J.B., Leveck, M.D., Marsiske, M., et al. (2002). Effects of cognitive training interventions with older adults: A randomized controlled trial. JAMA, 288(18), 2271-2281.

Benedict, R.H., Amato, M.P., Boringa, J., Brochet, B., Foley, F., Fredrikson, S., et al. (2012). Brief International Cognitive Assessment for MS (BICAMS): International standards for validation. BMC Neurol, 12, 55.

Benedict, R.H., Cookfair, D., Gavett, R., Gunther, M., Munschauer, F., Garg, N., \& Weinstock-Guttman, B. (2006). Validity of the 
minimal assessment of cognitive function in multiple sclerosis (MACFIMS). J Int Neuropsychol Soc, 12(4), 549-558.

Benedict, R.H., \& Walton, M.K. (2012). Evaluating cognitive outcome measures for MS clinical trials: What is a clinically meaningful change? Mult Scler, 18(12), 1673-1679.

Brassington, J.C., \& Marsh, N.V. (1998). Neuropsychological aspects of multiple sclerosis. Neuropsychol Rev, 8(2), 43-77.

Brenk, A., Laun, K., \& Haase, C.G. (2008). Short-term cognitive training improves mental efficiency and mood in patients with multiple sclerosis. Eur Neurol, 60(6), 304-309.

Brissart, H., Leroy, M., \& Debouverie, M. (2010). Cognitive rehabilitation in multiple sclerosis: Preliminary results and presentation of a new program, PROCOG-SEP. Rev Neurol (Paris), 166(4), 406-411.

Cerasa, A., Gioia, M.C., Valentino, P., Nistico, R., Chiriaco, C., Pirritano, D., et al. (2013). Computer-assisted cognitive rehabilitation of attention deficits for multiple sclerosis: A randomized trial with FMRI correlates. Neurorehabil Neural Repair, 27(4), 284-295.

Chiaravalloti, N.D., \& DeLuca, J. (2008). Cognitive impairment in multiple sclerosis. Lancet Neurol, 7(12), 1139-1151.

Chiaravalloti, N.D., DeLuca, J., Moore, N.B., \& Ricker, J.H. (2005). Treating learning impairments improves memory performance in multiple sclerosis: A randomized clinical trial. Mult Scler, 11(1), 58-68.

Chiaravalloti, N.D., Stojanovic-Radic, J., \& Deluca, J. (2013). The role of speed versus working memory in predicting learning new information in multiple sclerosis. J Clin Exp Neuropsychol, 35(2), 180-191.

Chiaravalloti, N.D., Wylie, G., Leavitt, V., \& Deluca, J. (2012). Increased cerebral activation after behavioral treatment for memory deficits in MS. J Neurol, 259(7), 1337-1346.

das Nair, R., Ferguson, H., Stark, D.L., \& Lincoln, N.B. (2012), Memory Rehabilitation for people with multiple sclerosis. Cochrane Database Syst Rev 3, CD008754.

das Nair, R., \& Lincoln, N.B. (2012). Evaluation of rehabilitation of memory in neurological disabilities (ReMiND): A randomized controlled trial. Clin Rehabil, 26(10), 894-903.

DeLuca, J. (2006). What We Know about Cognitive Changes in Multiple Sclerosis. In: N. LaRocca \& R. Kalb (Eds.), Multiple Sclerosis: Understanding the cognitive challenges (pp. 17-39). New York: Demos Medical Publishing.

DeLuca, J., Barbieri-Berger, S., \& Johnson, S.K. (1994). The nature of memory impairments in multiple sclerosis: Acquisition versus retrieval. J Clin Exp Neuropsychol, 16(2), 183-189.

DeLuca, J., Chelune, G.J., Tulsky, D.S., Lengenfelder, J., \& Chiaravalloti, N.D. (2004). Is speed of processing or working memory the primary information processing deficit in multiple sclerosis? J Clin Exp Neuropsychol, 26(4), 550-562.

Erickson, K.I., Voss, M.W., Prakash, R.S., Basak, C., Szabo, A., Chaddock, L., et al. (2011). Exercise training increases size of hippocampus and improves memory. Proc Natl Acad Sci U S A, 108(7), 3017-3022.

Fink, F., Rischkau, E., Butt, M., Klein, J., Eling, P., \& Hildebrandt, H. (2010). Efficacy of an executive function intervention pro- gramme in MS: A placebo-controlled and pseudo-randomized trial. Mult Scler, 16(9), 1148-1151.

Freeman, J.A., \& Playford, E.D. (2012). Rehabilitation therapy in MS; a short-term, expensive, placebo. Mult Scler, 18(10), 13791381 .

Goverover, Y., Basso, M., Wood, H., Chiaravalloti, N., \& DeLuca, J. (2011). Examining the benefits of combining two learning strategies on recall of functional information in persons with multiple sclerosis. Mult Scler, 17(12), 1488-1497.

Goverover, Y., Genova, H.M., Hillary, F.G., \& DeLuca, J. (2007). The relationship between neuropsychological measures and the Timed Instrumental Activities of Daily Living task in multiple sclerosis. Mult Scler, 13(5), 636-644.

Grima, D.T., Torrance, G.W., Francis, G., Rice, G., Rosner, A.J., \& Lafortune, L. (2000). Cost and health related quality of life consequences of multiple sclerosis. Mult Scler, 6(2), 91-98.

He, D., Zhou, H., Guo, D., Hao, Z., \& Wu, B. (2011). Pharmacologic treatment for memory disorder in multiple sclerosis. Cochrane Database Syst Rev (10), CD008876.

Higgins, J.P., Thompson, S.G., Deeks, J.J., \& Altman, D.G. (2003). Measuring inconsistency in meta-analyses. BMJ, 327(7414), 557-560.

Hildebrandt, H., Lanz, M., Hahn, H.K., Hoffmann, E., Schwarze, B., Schwendemann, G., \& Kraus, J.A. (2007). Cognitive training in MS: Effects and relation to brain atrophy. Restor Neurol Neurosci, 25(1), 33-43.

Kobelt, G., Berg, J., Lindgren, P., Fredrikson, S., \& Jonsson, B. (2006). Costs and quality of life of patients with multiple sclerosis in Europe. J Neurol Neurosurg Psychiatry, 77(8), 918-926.

Krupp, L.B., Christodoulou, C., Melville, P., Scherl, W.F., MacAllister, W.S., \& Elkins, L.E. (2004). Donepezil improved memory in multiple sclerosis in a randomized clinical trial. Neurology, 63(9), 1579-1585.

Krupp, L.B., Christodoulou, C., Melville, P., Scherl, W.F., Pai, L.Y., Muenz, L.R., et al. (2011). Multicenter randomized clinical trial of donepezil for memory impairment in multiple sclerosis. Neurology, 76(17), 1500-1507.

Landi, D., \& Rossini, P.M. (2010). Cerebral restorative plasticity from normal ageing to brain diseases: A "never ending story". Restor Neurol Neurosci, 28(3), 349-366.

Lincoln, N.B., Dent, A., Harding, J., Weyman, N., Nicholl, C., Blumhardt, L.D., \& Playford, E.D. (2002). Evaluation of cognitive assessment and cognitive intervention for people with multiple sclerosis. J Neurol Neurosurg Psychiatry, 72(1), 9398.

Lustig, C., Shah, P., Seidler, R., \& Reuter-Lorenz, P.A. (2009). Aging, training, and the brain: A review and future directions. Neuropsychol Rev, 19(4), 504-522.

Mattioli, F., Stampatori, C., Scarpazza, C., Parrinello, G., \& Capra, R. (2012). Persistence of the effects of attention and executive functions intensive rehabilitation in relapsing remitting multiple sclerosis. Multiple Sclerosis and Related Disorders, 1(4), 168-173.

Mattioli, F., Stampatori, C., Zanotti, D., Parrinello, G., \& Capra, R. (2010). Efficacy and specificity of intensive cognitive 
rehabilitation of attention and executive functions in multiple sclerosis. J Neurol Sci, 288(1-2), 101-105.

McCarthy, M., Beaumont, J.G., Thompson, R., \& Peacock, S. (2005). Modality-specific aspects of sustained and divided attentional performance in multiple sclerosis. Arch Clin Neuropsychol, 20(6), 705-718.

Mendozzi, L., Pugnetti, L., Motta, A., Barbieri, E., Gambini, A., \& Cazzullo, C.L. (1998). Computer-assisted memory retraining of patients with multiple sclerosis. Ital J Neurol Sci, 19, S431S438.

Moher, D., Liberati, A., Tetzlaff, J., \& Altman, D.G. (2009). Preferred reporting items for systematic reviews and metaanalyses: The PRISMA statement. PLoS Med, 6(7), e1000097.

Morrow, S.A., Drake, A., Zivadinov, R., Munschauer, F., WeinstockGuttman, B., \& Benedict, R.H. (2010). Predicting loss of employment over three years in multiple sclerosis: Clinically meaningful cognitive decline. Clin Neuropsychol, 24(7), 11311145 .

Morrow, S.A., Kaushik, T., Zarevics, P., Erlanger, D., Bear, M.F., Munschauer, F.E., \& Benedict, R.H. (2009). The effects of Lamphetamine sulfate on cognition in MS patients: Results of a randomized controlled trial. J Neurol, 256(7), 1095-1102.

Moss-Morris, R., McCrone, P., Yardley, L., van Kessel, K., Wills, G., \& Dennison, L. (2012). A pilot randomised controlled trial of an Internet-based cognitive behavioural therapy self-management programme (MS Invigor8) for multiple sclerosis fatigue. Behav Res Ther, 50(6), 415-421.

Motl, R.W., Sandroff, B.M., \& Benedict, R.H. (2011). Cognitive dysfunction and multiple sclerosis: Developing a rationale for considering the efficacy of exercise training. Mult Scler, 17(9), 1034-1040.

NICE. (2003). Management of MS in primary and secondary care. Clinical guideline 8. London: National Institute for Clinical Excellence.

NMSS. (2008). Assessment and Management of Cognitive Impairment in Multiple Sclerosis. Treatment Recommendations for Physicians. Retrieved July 6, 2013, from http://www.nationalmssociety.org/

O'Brien, A.R., Chiaravalloti, N., Goverover, Y., \& Deluca, J. (2008). Evidenced-based cognitive rehabilitation for persons with multiple sclerosis: A review of the literature. Arch Phys Med Rehabil, 89(4), 761-769.

Oswald, W.D., Gunzelmann, T., Rupprecht, R., \& Hagen, B. (2006). Differential effects of single versus combined cognitive and physical training with older adults: The SimA study in a 5-year perspective. European Journal of Ageing, 3(4), 179-192.

Owsley, C., Sloane, M., McGwin, G., Jr., \& Ball, K. (2002). Timed instrumental activities of daily living tasks: Relationship to cognitive function and everyday performance assessments in older adults. Gerontology, 48(4), 254-265.

Rao, S.M., Grafman, J., DiGiulio, D., Mittenberg, W., Bernardin, L., Leo, G.J., et al. (1993). Memory dysfunction in multiple sclerosis: Its relation to working memory, semantic encoding, and implicit learning. Neuropsychology, 7, 364-374.

Rao, S.M., Leo, G.J., Bernardin, L., \& Unverzagt, F. (1991). Cognitive dysfunction in multiple sclerosis. I. Frequency, patterns, and prediction. Neurology, 41(5), 685-691.
RevMan. (2012). Review Manager (RevMan) [Computer program] (Version Version 5.2.3). Copenhagen: The Nordic Cochrane Centre: The Cochrane Collaboration.

Rosti-Otajarvi, E.M., \& Hamalainen, P.I. (2011). Neuropsychological rehabilitation for multiple sclerosis. Cochrane Database Syst Rev (11), CD009131.

Rosti-Otajarvi, E.M., Mantynen, A., Koivisto, K., Huhtala, H., \& Hamalainen, P. (2013a). Neuropsychological rehabilitation has beneficial effects on perceived cognitive deficits in multiple sclerosis during nine-month follow-up. J Neurol Sci, 334(1-2), 154-160.

Rosti-Otajarvi, E.M., Mantynen, A., Koivisto, K., Huhtala, H., \& Hamalainen, P. (2013b). Patient-related factors may affect the outcome of neuropsychological rehabilitation in multiple sclerosis. J Neurol Sci, 334(1-2), 106-111.

Sandroff, B.M., Klaren, R.E., Pilutti, L.A., Dlugonski, D., Benedict, R.H., \& Motl, R.W. (2014). Randomized controlled trial of physical activity, cognition, and walking in multiple sclerosis. J Neurol, 261(2), 363-372.

Scarpazza, C., Braghittoni, D., Casale, B., Malagu, S., Mattioli, F., di Pellegrino, G., \& Ladavas, E. (2013). Education protects against cognitive changes associated with multiple sclerosis. Restor Neurol Neurosci, 31(5), 619-631.

Shatil, E., Metzer, A., Horvitz, O., \& Miller, A. (2010). Homebased personalized cognitive training in MS patients: A study of adherence and cognitive performance. NeuroRehabilitation, 26(2), 143-153.

Smith, A. (1982). Symbol Digit Modality Test, Western Psychological Services, Los Angeles, CA.

Solari, A., Motta, A., Mendozzi, L., Pucci, E., Forni, M., Mancardi, G., \& Pozzilli, C. (2004). Computer-aided retraining of memory and attention in people with multiple sclerosis: A randomized, double-blind controlled trial. J Neurol Sci, 222(1-2), 99-104.

Stern, Y. (2002). What is cognitive reserve? Theory and research application of the reserve concept. J Int Neuropsychol Soc, 8(3), 448-460.

Strober, L., Chiaravalloti, N., Moore, N., \& Deluca, J. (2013). Unemployment in multiple sclerosis (MS): Utility of the MS Functional Composite and cognitive testing. Mult Scler.

Stuifbergen, A.K., Becker, H., Perez, F., Morison, J., Kullberg, V., \& Todd, A. (2012). A randomized controlled trial of a cognitive rehabilitation intervention for persons with multiple sclerosis. Clin Rehabil, 26(10), 882-893.

Sumowski, J.F., Chiaravalloti, N., Erlanger, D., Kaushik, T., Benedict, R.H., \& DeLuca, J. (2011). L-amphetamine improves memory in MS patients with objective memory impairment. Mult Scler, 17(9), 1141-1145.

Sumowski, J.F., Rocca, M.A., Leavitt, V.M., Riccitelli, G., Comi, G., Deluca, J., \& Filippi, M. (2013). Brain reserve and cognitive reserve in multiple sclerosis: What you've got and how you use it. Neurology, 80(24), 2186-2193.

Sumowski, J.F., Wylie, G.R., Deluca, J., \& Chiaravalloti, N. (2010). Intellectual enrichment is linked to cerebral efficiency in multiple sclerosis: Functional magnetic resonance imaging evidence for cognitive reserve. Brain, 133( $\mathrm{Pt} 2)$, 362-374. 
Tesar, N., Bandion, K., \& Baumhackl, U. (2005). Efficacy of a neuropsychological training programme for patients with multiple sclerosis - a randomised controlled trial. Wien Klin Wochenschr, 117(21-22), 747-754

Thomas, P.W., Thomas, S., Hillier, C., Galvin, K., \& Baker, R. (2006). Psychological interventions for multiple sclerosis. Cochrane Database Syst Rev (1), CD004431.
Vogt, A., Kappos, L., Calabrese, P., Stocklin, M., Gschwind, L., Opwis, K., \& Penner, I.K. (2009). Working memory training in patients with multiple sclerosis - comparison of two different training schedules. Restor Neurol Neurosci, 27(3), 225-235. 